\title{
CORRECTIONS
}

\section{Author Correction: Functions and mechanisms of non-histone protein acetylation}

Takeo Narita (D), Brian T. Weinert and Chunaram Choudhary (1)

Nature Reviews Molecular Cell Biology 20, 156-174 (2019)

https://doi.org/10.1038/s41580-018-0081-3 Published online 22 November 2018

In the original Figure 1a, the side chain of acetyl-lysine was depicted incorrectly: the amino group was mistakenly omitted and the acetyl group was erroneously attached to the epsilon carbon. Instead, the acetyl group should be attached to the amino group. This has been corrected in the HTML and PDF versions of the article.

https://doi.org/10.1038/s41580-019-0156-9 | Published online 2 July 2019 